\title{
Assessment of Knowledge About Autism Spectrum Disorder Among Paediatricians
}

\section{Fatima Zia, ${ }^{1}$ Hafsa Qamar, ${ }^{2}$ Irum Aslam, ${ }^{3}$ Muhammad Asif Siddiqui ${ }^{4}$}

\begin{abstract}
Objective: To evaluate the frequency of Paediatricians who have good knowledge for diagnosis of Autism Spectrum Disorder (ASD).

Methods: It is cross-sectional study conducted in department of Paediatric Medicine, Children Hospital, Lahore, Jinnah Hospital and Services Hospital Lahore, in 6 months duration, spanning from June 27, 2016 till December 27, 2016. A total of 89 doctors fulfilling the inclusion criteria were registered after informed consent. Demographic data (including age, sex, qualification and duration of clinical experience) was taken. Doctors were given a questionnaire to assess their knowledge of ASD. The questionnaire was a nineteen-item self-administered questionnaire divided into four domains namely, social interaction (Domain 1), impairment in communication (Domain 2), repetitive behavior (Domain 3), characteristics of autism as a disorder and its comorbidities (Domain 4). The KCAHW sore $\geq 15$ was considered as good. Data was entered and analyzed in (SPSS) version 22.0.
\end{abstract}

Results: The mean age of subjects was $30.67 \pm 2.80$ years with $31(31 \%)$ physicians male and $69(69 \%)$ were females. The mean KCAHW score was 15.07 \pm 3.54 with minimum and maximum score of 7 and 19 . According to operational definition a total of $62(62 \%)$ subjects had good knowledge while $38(38 \%)$ physician had score $<15$.

Conclusion: Though $68 \%$ of paediatricians had good knowledge about childhood autism according to our study. The physicians who had poor knowledge, must be considered for different educational activities to enhance their knowledge regarding ASD, which may help in early diagnosis and improving prognosis of children with ASD.

Key Words: Paediatricians, Autism spectrum disorder

How to Cite: Zia F, Qamar H, Aslam I, Siddiqui MA. Assessment of knowledge about autism spectrum disorder among paediatricians. Esculapio.2020;16(04):83-86.

DOI: https://doi.org/10.51273/esc20.2516418

\section{Introduction}

A utism Spectrum Disorder (ASD) constitutes several clinical disorders, ranging from mild behavior disturbances to severe disability. Abnormal social interaction as well as communication plus repetitive and restrictive pattern of activities and behaviors are important features of ASD. Normal daily functioning of child may be affected and symp-

\begin{tabular}{|c|c|}
\hline 1. Fatima Zia & 2. Hafsa Qamar \\
\hline 3. Irum Aslam & 4. Muhammad Asif Siddiqui \\
\hline \multicolumn{2}{|c|}{ 1-4. PGR, Children's Hospital \& Institute of Child Health } \\
\hline \multicolumn{2}{|c|}{$\begin{array}{l}\text { Correspondence: } \\
\text { Dr Muhammad Asif Siddiqui, Department of Peads Medicine, Children } \\
\text { Hospital,Lahore.Email:drmasifrmc@gmail.com }\end{array}$} \\
\hline Submission Date: & $23-08-2020$ \\
\hline 1st Revision Date: & $17-12-2020$ \\
\hline Acceptance Date: & $13-01-2021$ \\
\hline
\end{tabular}

toms can be noted at an early age. ${ }^{1,2} \mathrm{ASD}$ incidence is increasing dramatically in children. In past it was rare, 1 st case was described by Kanner in year $1943^{3}$ but now prevalence is reported to be around $62 / 10,000$. $^{4,5}$ Many factors are responsible for this increase like well-defined diagnostic criteria even in mild forms for autism, awareness of both parents plus physicians and increase of true prevalence. ${ }^{6}$ Due to this high prevalence many pediatricians are now able to suspect and diagnose ASD during 18 to 36 months of life in children with abnormal communication, socialization or stereotypic behaviors. ${ }^{7}$ For early intervention, we need early diagnosis of the disease based on adequate knowledge, diagnostic criteria and availability of screening tools. Age of the child at which ASD is diagnosed first time is dependent on 
treating physician knowledge. ${ }^{8}$ According to a study average age for diagnosis of ASD was 4 years and 10 months.8 In one study, out of 167 participants, 51\% of participants had good knowledge, $49 \%$ had poor knowledge for Autism. ${ }^{9}$

In Pakistan, some of healthcare workers lack proper knowledge regarding ASD.10 Similarly other studies suggested different levels of knowledge (causes, treatment, prognosis, cognitive profiles of autism) for people having different professions or roles (health professionals, parents, teachers) involved in diagnosis of autism. Among healthcare professionals, pediatricians are more important because they are the first point of contact where children are reporting first time with abnormal behavior. Main focus of our study is to assess the knowledge of pediatricians required for diagnosis and treatment of autistic spectrum disorder. ${ }^{9}$

\section{Methods}

This is a Cross-Sectional Study conducted in departments of Paediatric Medicine, Children Hospital, Lahore, Jinnah hospital and Services Hospital Lahore in 6 months durations from June 27, 2016 till December 27, 2016. 100 paediatricians was included with $95 \%$ confidence interval, $10 \%$ margin of error and taking expected percentage of good knowledge i.e. $51 \%$ of pediatricians for diagnosis of ASD, using non probability purposive sampling technique. Whereas paediatricians with age range 26-35 years of both genders, having more than 1-year clinical experience in teaching hospital were included. Doctors who are not practicing for more than 6 months or doctors who are not permanently positioned in paediatric ward were excluded. 100 doctors fulfilling the inclusion criteria after informed consent were registered for the study.

Demographic data (including age, sex, qualification and duration of clinical experience) was taken. Doctors were given a questionnaire to assess their knowledge of ASD. Knowledge about Childhood Autism among Health Workers (KCAHW) Questionnaire was used. The questionnaire was a nineteen-item selfadministered questionnaire divided into four domains namely, social interaction (Domain 1), impairment in communication (Domain 2), repetitive behavior (Domain 3), characteristics of autism as a disorder and its comorbidities (Domain 4), the total score ranges 0-19 and good score was labelled as $>15$. Data was entered and analyzed in (SPSS) version 22.0. The quantitative variables age, years of experience and KCAHW score were expressed as mean and standard deviation. Frequency and percentage were calculated for qualitative data like gender and good knowledge i.e. KCAHW score $\geq 15$. Data will be stratified for age, gender, duration of experience (1-5, > 5 years) and qualification to deal with effect modifiers. Post stratification Chi-square test was applied taking pvalue $\leq 0.05$ as significant.

\section{Results}

The mean age of subjects was $30.67 \pm 2.80$ years with minimum and maximum age of $26-35$ years. There were $37(37 \%)$ subjects aged 26-29 years and 63(63 $\%$ ) doctors were $30-35$ years old. A total of 31(31\%) physicians male and 69(69\%) were females. According to duration of experience, 58(58\%) subjects had 1-5 years of clinical experience and $42(42 \%)$ subjects had $>5$ years of experience. There were $18(18 \%)$ students who were only graduate while $82(82 \%)$ were PG trainee as well. The mean KCAHW score was $15.07 \pm 3.54$ with minimum and maximum score of 7 and 19. A total of 62(62\%) subjects had good knowledge while $38(38 \%)$ physician had score $<15$. When data was stratified for age, gender and duration of experience, we found significant association of good score with these effect modifiers, $p$-value $>0.05$.

\section{Discussion}

Autism spectrum disorder is one of the fastest increa-

Table 1: Descriptive Statistics of Age (years) and KCAHW Scores

\begin{tabular}{lccccc}
\hline & Mean & S. D & Range & Min. & Max. \\
\hline Age (years) & 30.67 & \pm 2.80 & 9 & 26 & 35 \\
KCAHW* & 15.07 & \pm 3.54 & 12 & 7 & 19 \\
\hline
\end{tabular}

*Knowledge about Childhood Autism among Health Workers (KCAHW) Questionnaire

Table 2: Comparison of Good KCAHW Score and Age Groups

\begin{tabular}{ccccc}
\hline & & \multicolumn{2}{c}{ Good knowledge } & p- \\
\cline { 3 - 4 } value \\
\cline { 3 - 4 } Age groups & $26-29$ & $21(33.9 \%)$ & $16(42.1 \%)$ & 0.408 \\
(years) & $30-35$ & $41(66.1 \%)$ & $22(57.9 \%)$ & \\
Gender & Male & $20(32.3 \%)$ & $11(28.9 \%)$ & 0.728 \\
& Female & $42(67.7 \%)$ & $27(71.1 \%)$ & \\
Duration of & $1-5$ & $34(54.8 \%)$ & $24(63.2 \%)$ & 0.413 \\
experience (years) & $>\mathbf{5}$ & $28(45.2 \%)$ & $14(36.8 \%)$ & \\
\hline
\end{tabular}


sing disorders in children throughout the whole world and it is lifelong disorder affecting neuronal development in children hence can be characterized by the symptoms like impaired non-verbal and verbal communication, impaired socialization and restricted behavior and interest patterns. ${ }^{11}$ There are many studies in current age that are being done related to this disorder but these studies suggest different variation and levels of knowledge in healthcare workers and professionals that directly influences treatment diagnosis and prognosis of this disease. ${ }^{12}$

\section{Good knowledge}

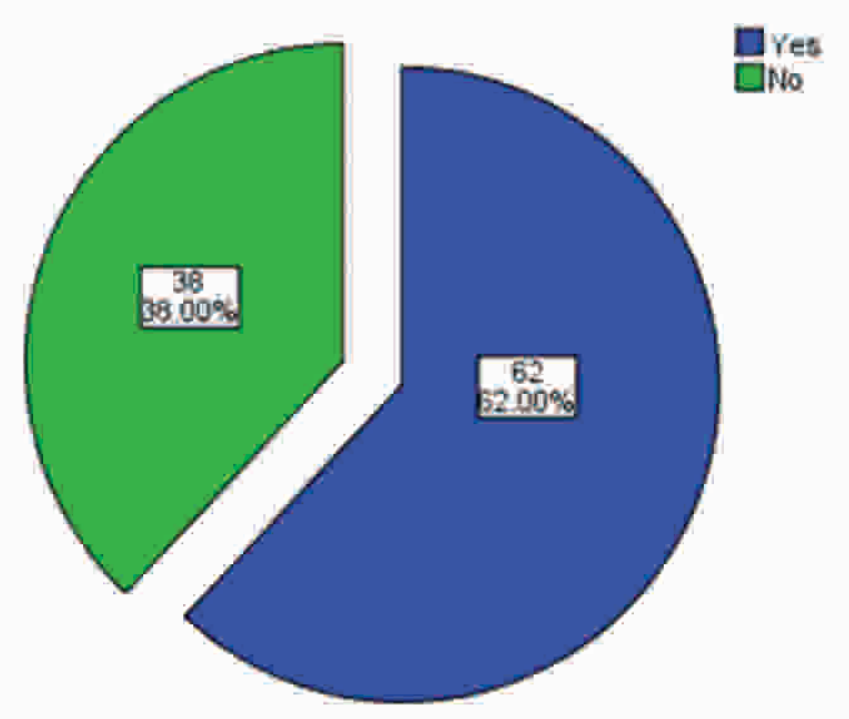

Fig-1: Distribution of Good Score

Variations of knowledge regarding Autism, may present in primary health care providers for example family physicians and family pediatricians and in comparison to specialist like speech therapist child psychiatrist and psychologist according to one survey done in United States. ${ }^{13}$ Professionals of healthcare in countries that are underdeveloped also have low levels of knowledge regarding ASD.$^{14}$ Pediatricians are first point for contact, so they must have proper knowledge regarding autism spectrum disorder. ${ }^{15}$ In Pakistan healthcare professionals still have questionable assessment regarding this disorder. ${ }^{16}$

In the year 2011, one study observed baseline misconceptions and knowledge related to autism in healthcare professionals of Pakistan. ${ }^{10}$ In this study mean subjects age was $30.67 \pm 2.80$ yrs. with 31 (31 $\%)$ male and $69(69 \%)$ physicians females. Accurate knowledge regarding DSM IV TR criteria of diagnosis regarding autism was main focus of the study but in different professionals' variations were noted related to proper use of this criteria in diagnosis of autism.
Non physicians had more chances of diagnosing autism correctly than physicians. (P value $<0.001){ }^{10}$ Similar results were seen in another study done in one of the African countries. ${ }^{17}$ Our study was done on paediatricians only with mean KCAHW score as $15.07 \pm 3.54$ with maximum and minimum score as 19 and 7 only. Total $62 \%$ of respondents had good knowledge and $38 \%$ of physicians had less than 15 score. So, our study showed 38\% paediatricians had poor knowledge regarding autism spectrum disorders, which in turn may affect early diagnosis and prognosis of children with autism spectrum disorder. There is need to conduct studies on larger scale prospectively with imparting learning of autism spectrum disorder using different educa-tional activities and comparing pre and post educational activities results regarding knowledge of autism spectrum disorder in health care workers.

Hence it is concluded that some pediatricians may need to improve their knowledge regarding autism spectrum disorder. ${ }^{18}$

\section{Conclusion}

Though $68 \%$ of paediatricians had good knowledge about childhood autism according to our study. The physicians who had poor knowledge, must be considered for different educational activities to enhance their knowledge regarding ASD, which may help in early diagnosis and improving prognosis of children with ASD.

\section{Conflict of Interest: $\quad$ None}

\section{References}

1. Ramaswami G, Geschwind DH. Genetics of autism spectrum disorder. In Handbook of clinical neurology 2018 Jan 1 (Vol. 147, pp. 321-329). Elsevier.

2. Li K. The (re-) instrumentalization of the Diagnostic and Statistical Manual of Mental Disorders (DSM) in psychological publications: a citation context analysis. arXiv preprint arXiv:2010.11101.2020 Oct 21.

3. Muratori F, Bizzari V. AUTISM AS A DISRUPTION OF AFFECTIVE CONTACT: THE FORGOTTEN ROLE OF GEORGE FRANKL. Clinical Neuropsychiatry. 2019Aug 1;16(4).

4. Chiarotti F, Venerosi A. Epidemiology of Autism Spectrum Disorders: A Review of Worldwide Prevalence Estimates Since 2014. Brain Sciences. 2020 May; 10(5):274. 
5. (13) (PDF) THE GLOBAL PREVALENCE AND DIAGNOSIS OF AUTISM SPECTRUM DISORDER (ASD) AMONG YOUNG CHILDREN [Internet]. [cited 2020 Dec 28]. Available from: https:// www.researchgate.net/publication/336676984_THE _GLOBAL_PREVALENCE_AND_DIAGNOSIS OF_AUTISM_SPECTRUM_DISORDER_ASD_A MONG_YOUNG_CHILDREN

6. Manohar H, Kandasamy $\mathrm{P}$, Chandrasekaran V, Rajkumar RP. Early Diagnosis and Intervention for Autism Spectrum Disorder: Need for PediatricianChild Psychiatrist Liaison. Indian journal of psychological medicine. 2019 Jan;41(1):87-90.

7. Kliegman R, Stanton B, Schor N, St. Geme III J, Behrman R. Nelson Textbook of Pediatrics. 21st ed. Philadelphia: Elsevier 2019.

8. Altay MA. Family Physicians' Awareness of Autism Spectrum Disorder: Results from a Survey Study. Open access Macedonian journal of medical sciences. 2019 Mar 30;7(6):967.

9. Hayat AA, Meny AH, Salahuddin N, Alnemary FM, Ahuja KR, Azeem MW. Assessment of knowledge about childhood autism spectrum disorder among healthcare workers in Makkah-Saudi Arabia. Pakistan journal of medical sciences. 2019 Jul;35(4):951.

10. Imran N, Chaudry MR, Azeem MW, Bhatti MR, Choudhary ZI, Cheema MA. A survey of Autism knowledge and attitudes among the healthcare professionals in Lahore, Pakistan. BMC pediatrics. 2011 Dec 1;11(1):107.

11. Ivanov MV, Simashkova NV, Kozlovskaya GV, Makushkin EV. The epidemiologic study of the risk of autism spectrum disorders in children of 16-24 months in Russia, 2015-2016. Zhurnal nevrologii i psikhiatrii imeni SS Korsakova. 2018;118(5. Vyp.
2):12-9.

12. Xu G, Strathearn L, Liu B, Bao W. Corrected prevalence of autism spectrum disorder among US children and adolescents. Jama. 2018 Feb 6;319(5):505-.

13. Heidgerken AD, Geffken G, Modi A, Frakey L. A survey of autism knowledge in a health care setting. J Autism Dev Disord. 2005;35(3):323-30.

14. Bakare MO, Agomoh AO, Ebigbo PO, Eaton J, Okonkwo KO, Onwukwe JU, et al. Etiological explanation, treatability and preventability of childhood autism: a survey of Nigerian healthcare workers' opinion. Ann Gen Psychiatry. 2009;8(1):6.

15. Karande $\mathrm{S}$. Autism: A review for family physicians. Indian J Med Sci. 2006;60(5):205.

16. Bhat BA, Hussain A, Qadir W, Dar SA. Sociodemographic and clinical profile of children with autism spectrum disorders-An observational study from a tertiary care hospital. BLDE University Journal of Health Sciences. 2019 Jul 1;4(2):72.

17. Eseigbe EE, Nuhu F, Sheikh TL, Eseigbe P, Sanni K, Olisah V. Knowledge of childhood autism and challenges of management among medical doctors in Kaduna State, Northwest Nigeria. Autism Res Treat. $2015 ; 2015$.

18. Sampson WG, Sandra AE. Comparative study on knowledge about autism spectrum disorder among paediatric and psychiatric nurses in Public Hospitals in Kumasi, Ghana. Clinical practice and epidemiology in mental health: CP \& EMH. 2018;14:99.

\section{Author's Contribution}

ZF, QH, AI, SAM: Concept, design, interpretation, drafting 